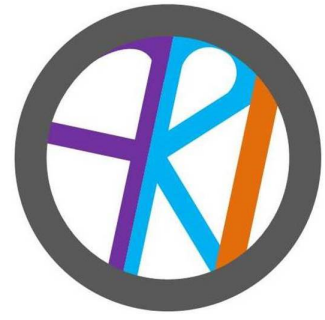 \\ ART | RESEARCH \\ intermational \\ A Transdisciplinary Journal
}

\section{A CANADIAN SELVAGE: WEAVING ARTISTIC RESEARCH INTO RESOURCE POLITICS}

Ruth Beer

Emily Carr University of Art and Design

rbeer@ecuad.ca

Caitlin Chaisson

Emily Carr University of Art and Design

cchaisson@ecuad.ca

Ruth Beer is an artist/researcher whose artwork has been presented in national and international exhibitions. Her recent research creation projects supported by SSHRC include "Trading Routes: Grease Trails, Oil Pipelines" which addresses energy and communities in transition within the interlaced geography of traditional Indigenous trading routes and proposed oil pipelines in Canada's northwest.

Caitlin Chaisson is an interdisciplinary artist, writer, and independent curator. She is the founder of Far Afield, an initiative that supports rural and regionally-connected artistic and curatorial practices. Her writing has appeared in Canadian Art, C Magazine, Espace, Momus, and the journal Drawing: Research, Theory, Practice, among others.

Abstract: This exploratory article addresses our experiences as artist-researchers engaged with "Trading Routes: Grease Trails, Oil Futures," a research-creation project supported by the Social Sciences and Humanities Research Council of Canada. "Trading Routes" focuses on the intersecting geographies of Indigenous fish grease trails and the proposed Alberta-British Columbia oil pipeline. These converging routes are shedding light on the present entanglement between Indigenous and non- 
Indigenous cultural heritage, ecological perspectives, and resource extraction. Through artistic scholarship, material production, historical and cultural understanding, we seek to better account for the ways in which an environmental social justice perspective can be crafted into arts-based research. We write from a point of reflection, where we assess, evaluate, disentangle, and unclad some of the learning that has come to us through the research-creation and presentation of contemporary weaving. We suggest that arts-based research can offer a methodology of learning and thinking rooted in a perspective of informing, informality, or thinking about artworks in form, an extension of $\mathrm{a} / \mathrm{r} /$ tographic praxis that is grounded in an analysis of materiality and aesthetics.

Keywords: oil; resource extraction; fish; weaving; contemporary art; Canada 
"It is assumed that history is not a seamless web but rather a web of which the warp and the woof [of] space and time, [are] woven in a very uneven fashion and producing distorted patterns."

- Harold Innis, The Bias of Communication, xvii

At a time when social and political discourses around extraction and energy transition in Canada seem prone to unravel, how can we keep from social and ecological collapse? In this exploratory article, we seek to better understand the way in which an environmental social justice perspective can be crafted into arts-based research. Specifically, we will explore how we have come to understand weaving as both process and product, that enables a vital mode of inquiry in relation to resource politics in Canada. Textiles are often used as a metaphor for social cohesion - from figures of speech like our "social fabric" and "common threads" to "homespun attitudes" - but what has been less examined is the way in which textiles offer a mode to better understand the relationship between opposing and complex vectors of action. In weaving, the warp and weft have perpendicular orientations and the cohesion is not a result of singularity, but of the intersection of divergent paths. The co-presence of these trajectories is what gives the material its flexibility as well as its strength. How can weaving inspire us to think more critically about complex systems? In what way is the production of weaving an ecological act? Taking an intersectional disciplinary approach, what conceptual openings can be made in our understanding of resource politics in Canada by situating textiles alongside a resource like oil?

These converging routes are shedding light on the entanglement between Indigenous and non-Indigenous

In order to explore this, we will address research that has been generated cultural heritage, ecological through our engagement with "Trading Routes: Grease Trails, Oil Futures," a Social Sciences and Humanities Research Council project led by artist and researcher Ruth Beer, with research assistance from Caitlin Chaisson. Through artistic practice, historical understanding, and research-based inquiries, "Trading Routes" focuses on the intersecting geographies in Canada's Northwest of historical Indigenous trade corridors (specifically oolichan fish "grease" trails for transporting fish oil), and the sites of recent contentious proposals to build pipelines for transporting fossil fuels and tar sands oil from Alberta to the British Columbia coast, including over unceded Indigenous territories. These converging routes are shedding light on the entanglement between Indigenous and non-Indigenous cultural heritage, ecological perspectives, and resource extraction. The project uses the production of artworks and exhibitions to think through what it may mean to momentarily divorce oil from politics or capital and look at it through interdisciplinary research 
creation methodologies, merging socially-engaged art practice and pedagogy (Leavy; Rogoff; Rose; Sullivan) with cultural forms of knowledge. The qualitative project is guided by research methodologies that are flexible, reflexive, and remain open to poetic, unexpected, and challenging exchanges throughout the research process.

As settler urbanites based in Vancouver we are guided by questions that look to address the complex interweaving of culture, community, and the environment rather than thin descriptions and seamless narratives of energy debates in popular media. As such, our research involves extensive fieldwork in remote northern regions directly impacted by energy infrastructure projects and a rigorous process of ethics approvals to ensure proper permissions and protocols are followed within diverse cultural communities. As artist-researchers, we write from a point of reflection, where we assess, evaluate, disentangle, and unclad some of the learning that has come to us through the production and presentation of contemporary weaving. Recent emphasis on textiles, and weaving in particular, in major contemporary art exhibitions such as the Venice Biennale, is reflective of an increasing focus on related materials, processes and the broad expressive potential of weaving within art, design, and art education programs in Canada.

Our project is situated within a post-secondary context at Emily Carr University of Art and Design, where a renewed interest and scholarly approach to contemporary craft is emerging. As Elissa Auther has effectively argued, craft has long been perceived as "hampered," or unserious, in relation to fine art practices because of its relationship to utility or functionality (xvi). Like Auther, we question the motives and politics behind such a limited view of the relationship between art and craft, and see craft as offering a vital and rigorous perspective on the world. In what follows, we will foreground a variety of forms of research creation, from material exploration, to community engagement, to contextualizing the insights that both inspired the work and emerged through it. This process has enabled us to understand the production and presentation of artwork as a contemplative form of action, which can be used to create connections and illuminating encounters. Our process will be shared in this article through a deep examination of a number of specific artworks. By focusing on one facet of the research project's artistic production - weaving - we will further explore the relationships and entanglement between textiles, resource extraction, and the colonial legacy of Canada.

The "Trading Routes" project is distinctly aligned in relation to an emerging realm of energy humanities (After Oil; LeMenager and Foote), a relatively new academic discipline which demonstrates a growing recognition that in our contemporary Western culture, our relationship to energy is one that is as much a question of qualitative cultural and social customs as it is the quantifiable measures of geological, scientific, 
and commercial practices. The cultural perspective of the energy humanities creates new considerations for art education and interdisciplinary creative practices. We believe in the need for arts-based research approaches and affective artistic methodologies to address environmental issues from an educational perspective. Increasingly, and alarmingly, the relationship between environmentalism and education appears to be developing some troubling tendencies, particularly as evidenced in daily social interactions in the public sphere. As community organizers Matt Hern and Am Johal express in their book, Global Warming and the Sweetness of Life: A Tar Sands Tale, "so much of the environmental movement reverts to the language of education, or We need to educate people about the issues. This position claims that the real problem is that most people just don't have enough information, or are not sufficiently versed in the issues" (83; original emphasis). As Hern and Johal elaborate, this kind of positioning can only set-up relationships based on condescension or ignorance, neither of which are productive standpoints for fostering change.

Arts-based research, on the other hand, with an acceptance of openness, ambiguity, and "soft boundaries" (Bresler; White et al.), can become even more important in polemical discourses. Rather than espousing theories, data sets, or claims to objectivity, artistic experience "invites discoveries, emergent issues and ideas, mobilizes ways of seeing and being" (Bresler 56) through processes that are internalized by researchers and participants. This kind of framework shares an affinity with craft, in that "craft does involve knowledge that can be set down, but this is always a matter of incomplete approximation because artisanal skill is personal, intuitive, and capricious (in the sense that its results will be different in each set of hands, and from one piece of raw material to another)" (Adamson 60). Embracing the plurality of these personal and intuitive educational and pedagogical experiences is vital to shaping new approaches to the environmental debate.

We would like to suggest that arts-based research can offer a counterpoint to the kind of problematics addressed by Hern and Johal by pursuing a methodology of learning and thinking rooted in a perspective of informing, informality, or thinking about artworks in/form. This idea builds upon Ruth Beer's extensive work with a/r/tography which "provokes the creation of situations through inquiry" (Irwin et al. 71), where the arts are used as a way of re-searching the world to enhance understanding. We take in/ form as a methodology that extends a/r/tographic praxis in a new direction, by grounding the analysis in materiality and aesthetics. In/form is also particularly sensitive to the way in which "the handcrafted object reflects not only an informal economy of energy (as opposed to one of process efficiency), but also pleasure" (McCullough 10). We will address our informal experiences as artist-researchers through writing that is structured in a fashion that resembles the warp and weft of a textile. We suggest a 
weaving together of divergent and dialogical strands that loop and bind subjects as diverse as materiality, resources, spatiality, distance, and Canada's colonial history, in order to enrich the discourse surrounding contested geographies and extractive industries.

\section{Resource Staples: From Textiles to Oil}

North America's complex relationship to natural resources stems from many historical precedents, and our research has narrowed its focus to the ways in which the Canadian nation-state has been spun out of a resource-based economy. Natural resources are part of what seminal Canadian economist and communication theorist Harold Innis has specified as staples, "semi-processed export-oriented raw materials" (The Fur Trade in Canada v). Today, there is no doubt oil is heralded as the nation's prevailing staple: after minerals, lumber, fish, wheat, and fur. The exploration of the continent began with the luxuries of fur. Early merchants arrived seeking new wealth, becoming reliant on the expertise and knowledge of Indigenous peoples' tracking, hunting, and trapping skills. In exchange for animal pelts, dry goods and tools would be acquired. Among these goods, coarse woolen textiles commonly referred to as strouds, and the point blankets which would later be associated with the Hudson's Bay Company, were unsurpassed in demand. Essentially trading various textile materials in raw or processed states, fur for blankets, "for over a century, strouds played a hitherto unrecognized but stunningly large part in the North American fur trade" (Willmott 226). The fur trade in pre-federation Canada was sustained by European fashion industries, but the sartorial impulse very quickly unveiled a new political project. The resource wealth of the land and the immediate profitability of trading pelts consolidated European desires to settle the Northern part of the continent. By 1863, the Hudson's Bay Company underwent a major organizational shift headed by railway entrepreneur, Edward Watkins, who "tried to transform a fur-trade business into a huge colonization company" (Otter 176); an enterprise in governance that would instead be completed by delegates in parliament just four years later in the narrow margins between politics and commerce.

Today, Canada's trap is carbon-based. Fossil fuels have underscored the wealth of the nation at the same time as they have put national and ecological sovereignty at risk. We are caught in a very compromising position. Whereas "cloths were used as early currency" (Plant 62) in the beginnings of the Canadian nation-state, today our reliance on oil is the new tender. These kinds of shifts have profound effects on the public sphere. Oil underpins daily experience in an undeniably public way, despite the "ever-more-privatized nature of both actual resources and knowledge about the powers that control them" (Biemann et al. 76). Often unseen, oil is the quasi-invisible force that 
shapes the modern world. Weaving, in the context of our project, offers a necessary texture to the typically slick rhetoric of oil. Focusing on artistic scholarship and materiality, we will explore the ways fibers, land, and networks penetrate both woven fields and resource fields, and how arts-based research can support critical reflexivity when addressing some of these connections.

\section{Form and Content: Fiber and Land}

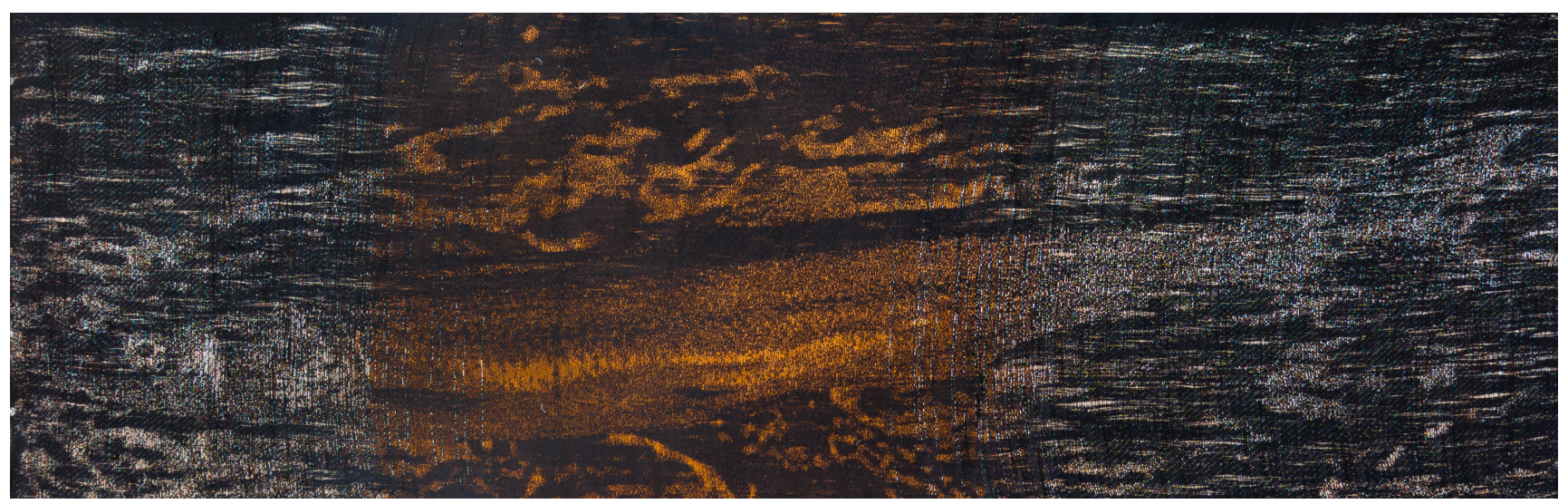

Figure 1. Ruth Beer. Fish. 2014. Jacquard woven tapestry; copper magnetic wire, aluminum wire and cotton, $55 \times 172 \mathrm{~cm}$. Image courtesy of the artist.

In the context of "Trading Routes," a deeper and more nuanced understanding of the materiality of natural resources, including their processing and transformation, has been a driving force. Since 2014, Ruth Beer has been testing unique and unconventional materials for inclusion in the weaving process. Beer's expertise in sculpture and material manipulation meant that she came to weaving with a particular attentiveness to the three-dimensional potentiality of woven matrices, and was invested in developing tacit knowledge of how fiber might substantially contribute to the field of sculpture (Robertson and Vinebaum) and further artistic excellence. Working within the signature of research creation, this foray into weaving adhered to integrated processes of research and production, which were created for the purposes of dissemination.

As the "basic element of all textile techniques" (Böhme 52), pliable fiber is the foundation of any woven material, and has an "immense semiotic capacity [...] be it as a currency, a sign of wealth, a transmitter of political authority, a creator of ties between people and kinship groups" (Auther 171). Through this project, it became important to consider how the properties of the threads could themselves display a contentious relationship to land. Fish (fig. 1) is a Jacquard loom weaving of copper, aluminum, and cotton. The metallic filaments produce an iridescent effect, imitative of the shimmer of fish scales and the rippling of water. But, the lustrous presence of the copper and 
aluminum fibers in the weaving cast light on the pernicious tangle of aquatic environments and heavy industry, which we were informed about, first-hand, from conversations with artists, activists, elders, teachers, curators, and other cultural workers during travel to sites that would be impacted by proposed oil pipeline infrastructure along the Pacific Northwest Coast. To be more specific, Fish is a depiction of an oolichan: a small, elongated organism whose marine existence is just as important as its legacy on land. For many coastal and inland First Nations, the oolichan's oily fat content is an important dietary supplement. Dried oolichan, sometimes called candlefish, is a source of fuel for burning. Traditionally, the fish would be ceremoniously harvested in the early spring when they swim from the ocean to the rivers to spawn. After the harvest, oolichan fat would be rendered and the resulting oil (grease) packed for trade along ancient "grease trails" which run from the Pacific coastal corridor to the interior of British Columbia.

The oolichan is tremendously important to the Haisla First Nation in Kitimaat Village, where the fish has dietary, pharmaceutical, and ceremonial purpose. Yet, in the past six decades, the oolichan population in Kitimaat has decreased to the point of virtually no river returns in 2000, according to the Department of Fisheries and Oceans ("Eulachon (Pacific Population)"). In the 1950s, the Provincial Government invited Alcan (now Rio Tinto Alcan) to develop an aluminum smelting plant in the region. With the resulting influx of industry workers, the new municipality of Kitimat was developed causing radical change to the surrounding ecosystems. In Monkey Beach, the awardwinning fictional novel by Haisla/Heiltsuk writer Eden Robinson, the disappearance of oolichan and the industrial despoilment of the region is tightly tethered to the presence of Alcan (Robinson; Soper-Jones 27). As more factories and people arrived, industrial and municipal effluent discharges made oolichan fishing impossible on the Kitimat river by 1972, and nearby rivers have suffered spawning declines to the extent that there are "no longer harvestable numbers of oolichan in the area" (Moody 33). The portrait of the oolichan in the weaving Fish pictures the tragic irony of the decimation of this tiny species of smelt by a distinctly synthetic process of smelting. To capture the oolichan's likeness in a weaving is to remember that "textile images are never imposed on the surface of the cloth: their patterns are always emergent from an active matrix, implicit in a web which makes them immanent to the processes from which they emerge" (Plant 67). The matrix within which the oolichan finds itself entangled is one where the clarity of Fish oscillates, fading in and out of focus. Depending on the way in which the light catches on the metals, the image of the oolichan is easily washed out.

In 2015, Fish was included in an exhibition of artworks at the Gulf of Georgia Cannery Museum in Steveston, British Columbia, once considered the "salmon capital of the world" ("Steveston Recollections"). The Cannery, which is now a federally-owned 
Parks Canada National Historic Site, was first built in 1894 and became one of the most productive canneries along the Fraser River. Today, the building is an important monument that preserves and presents the history of West Coast fishing. It is a popular site for school field trip excursions, and a destination for tens of thousands of local and international visitors. The exhibition, organized by Ruth Beer and fellow researcher Kit Grauer, took place in the flexible feature exhibit space, nestled between the towering production lines once used for salmon canning and herring reduction. Entitled "Trading Routes: Rivers, Fish and Oil," the exhibition included work by "Trading Routes" researchers, as well as local and visiting artists of Indigenous and non-Indigenous heritage. Intervening in the space of the historic museum, the artwork offered a very different experience for both visitors and interpreters. Several viewers expressed their interest in the open possibilities for interpretation of the artworks, and the challenge of engaging with the artworks' affective communication rather than the more familiar reliance on didactic frameworks of text panels and expository tools typically available in historical museums. In the 2015 annual report, the museum indicated the partnership was one of the major highlights of the year as it created a unique space for important discussions on the impact of resource development on river systems ("2015 Annual Report"). Housed within the informal educational setting of the Cannery, the exhibition was able to provide insight into the relationship between aquatic ecosystems and resource extraction in the artworks in a way that differed significantly from the research taking place in the studio. Looking to the space surrounding the artwork, other aspects of the formal qualities of the weavings enacted new dialogues with the existing historical displays. For instance, the weavings drew unexpected parallels with the synthetic mesh netting of the seine fishing displays found in other parts of the museum; and the reflective surface of the metallic cans created a dialogue with the sheen of copper and aluminum in the weavings. Surprising questions arose for visitors by the juxtaposition of these displays, allowing new associations and understandings to be formed.

\section{Oil, Felt from Some Distance}

In Canada, a self-declared "energy superpower," most people are not immune to thinking about what the energy futures hold for the environment, for the economy, and for Indigenous peoples. As artist-researchers, we feel close and deeply entrenched in these issues, not only in our research, but in our everyday life. And, like most other citizens living in densely populated urban areas, we simultaneously feel seriously removed from the effects of oil. This inspired us to set out to better understand this vexing distance. This sensation - of feeling deeply involved with something, though not exactly knowing our place in relation to it - bears some similarity to the aesthetic experience. Could we, and those we engage with, better understand our position to oil through arts-based practice? As Liora Bresler suggests, 
the concept of aesthetic distance is highly relevant to both art and research...the distance between our own self and our perceptual, emotional state. Aesthetic distance ensures deeper understanding of the aesthetic object: It is located at the midpoint between excessive distance- that is, not having an active interest in the object- and insufficient distance: being too close to the object where the work of art ceases to function as a symbol and is perceived as part of reality. (58)

This "midpoint" of distance is a productive site where deep engagement can take place. While the material experimentation with a work such as Fish allow us to more clearly see, perceive, and apprehend the relationship between the fibers and extraction landscapes, we were also eager to understand the way in which the manipulation of these threads could help us better understand questions of positionality and relationality. This led to an examination of the shared qualities between weaving and mapping.

Textile threads "form routes, vectors, and markings that connect points in space and render spatial topologies accessible, making them quasi pre-cartographic instruments of measure and orientation" (Böheme 51). We began to think through Western geography's banded strings of latitude and longitude as the axes along which space is cordoned, a loom whose threads can cut through ecological complexities and the socio-cultural expanse. Knowing that traditional mapping strategies have made it possible to point to sites where resources can be extracted, our attention turned to the conditions following extraction, including ways of looking at unfamiliar landscapes where new maps are needed. How do we map after oil has levelled and perforated the horizon, and spread out to coat the surfaces of the earth? What would a viscous map look like?

Oil Topography (fig. 2) is a three panel weaving that makes reference to land through a title that explicitly connects the artwork to mapping practices. With this reference, the weaving's abstract imagery takes on a more representational appearance, bearing compositional and graphic similarities to elevation keys in maps. Topographic keys are two-dimensional representations of the Earth's surface relief, which depict natural and man-made formations on the terrain. In this two-dimensional rendering, peaks and valleys are flattened into rings of changing colours, indicating areas of height and depth. Yet, the association of Oil Topography to mapping is easily usurped by another vision, that of an unstable liquid: oil. The terrain of Oil Topography simultaneously appears to be fluid and rippling, seeping over the edges of the woven panels. Then, our vision shifts once again, and the emulsification of oil appears with a distinctly celestial effect. The bird's-eye-view of this work becomes tripled: the viewer 
can see a topographic landscape, an encroaching spill, or the heavens all at once. The weaving begs the question of scale and scope. As a viewer, how far away, exactly, do we distance ourselves from the implications of oil? Can oil be astral and buried all at the same time?

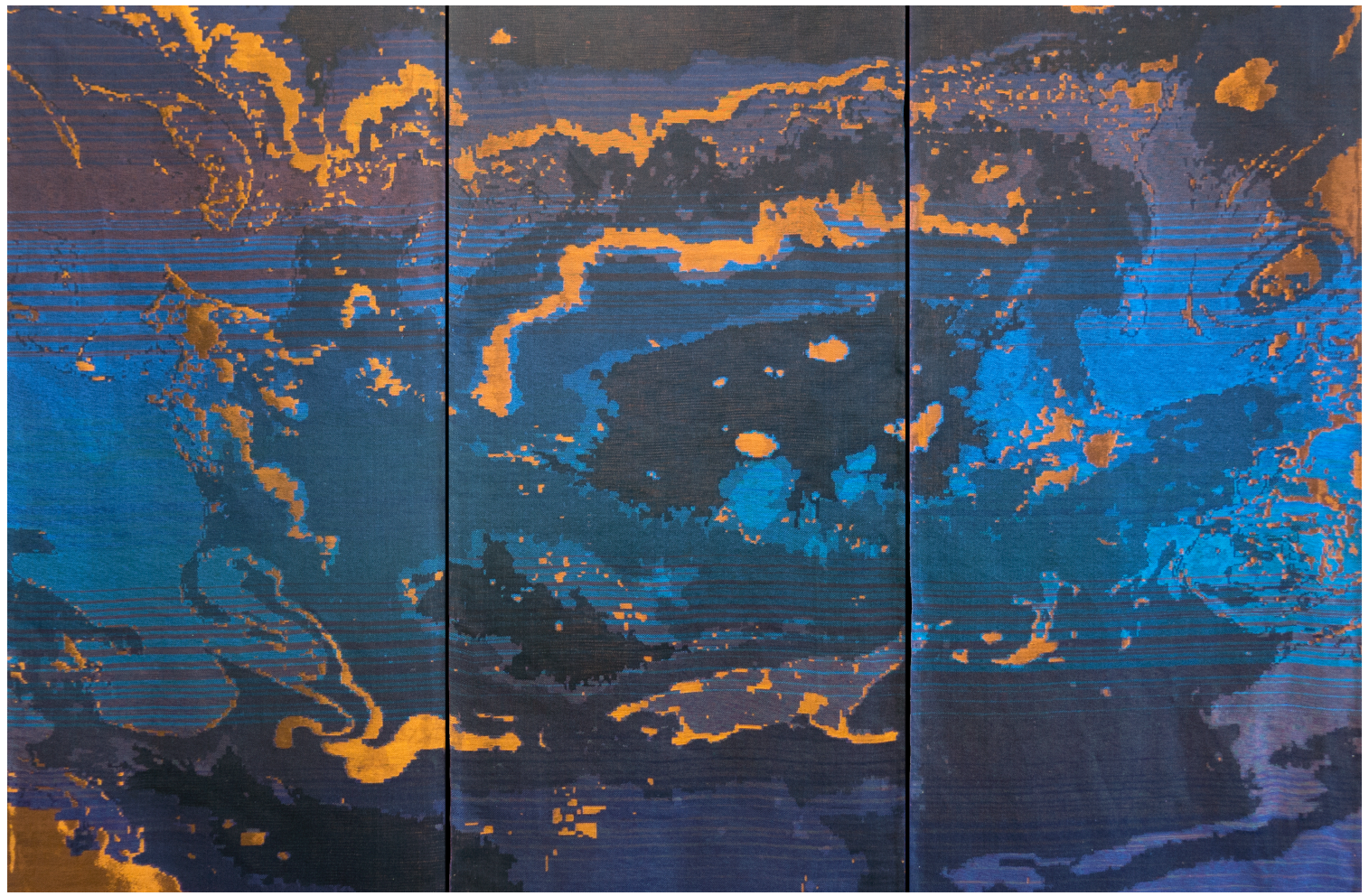

Figure 2. Ruth Beer. Oil Topography. 2014. Three panel Jacquard woven tapestry of copper magnetic wire, polyester, cotton, 304 × $218 \mathrm{~cm}$. Image courtesy of the artist.

This exploration of distance was advanced further through a living inquiry that took place in the Fraser Valley of British Columbia. Through museum and educational programming, multi-modal, aesthetic, and physical artwork can provide an entrance point to local communities to talk about complicated issues in ways that go beyond historical or written research methods. Oil Topography was presented in the exhibition "States of Matter" at the Reach Gallery Museum in Abbotsford, British Columbia. In conjunction with the exhibition, several accompanying community outreach and educational programs were developed that allowed for prolonged engagement with both the artworks and the issues at stake. In many respects, these activities allowed participants, museum-goers, and viewers, an opportunity to "linger" in the aesthetic experience (Bresler 55). The first event was a panel discussion, entitled "Art, the Environment and Wellness." Speakers included Ruth Beer, scholar and curator Beth Carruthers, artist Judith Currelly, artist and educator Sandra Semchuck, and Fraser Valley environmentalist John Vissers. Situated in the gallery amidst the artworks, it was 
clear just how closely people were positioning themselves amidst environmental issues, like the proposed pipeline. Emotions surfaced, and some audience participants were even moved to tears in the question period when speaking about their experiences and concerns about the impact extraction projects have on their own wellness. A few days following the panel discussion there was also an "embodied mapping" activity. John Vissers guided participants along a walk of the existing Kinder Morgan Trans-Mountain pipeline on Sumas Mountain, which is presently slated for expansion, despite major controversy. In accounts from both of these activities, participants had an opportunity to inform each other about personal experiences, affectations, uncertainties, concerns, and visions of change for the future.

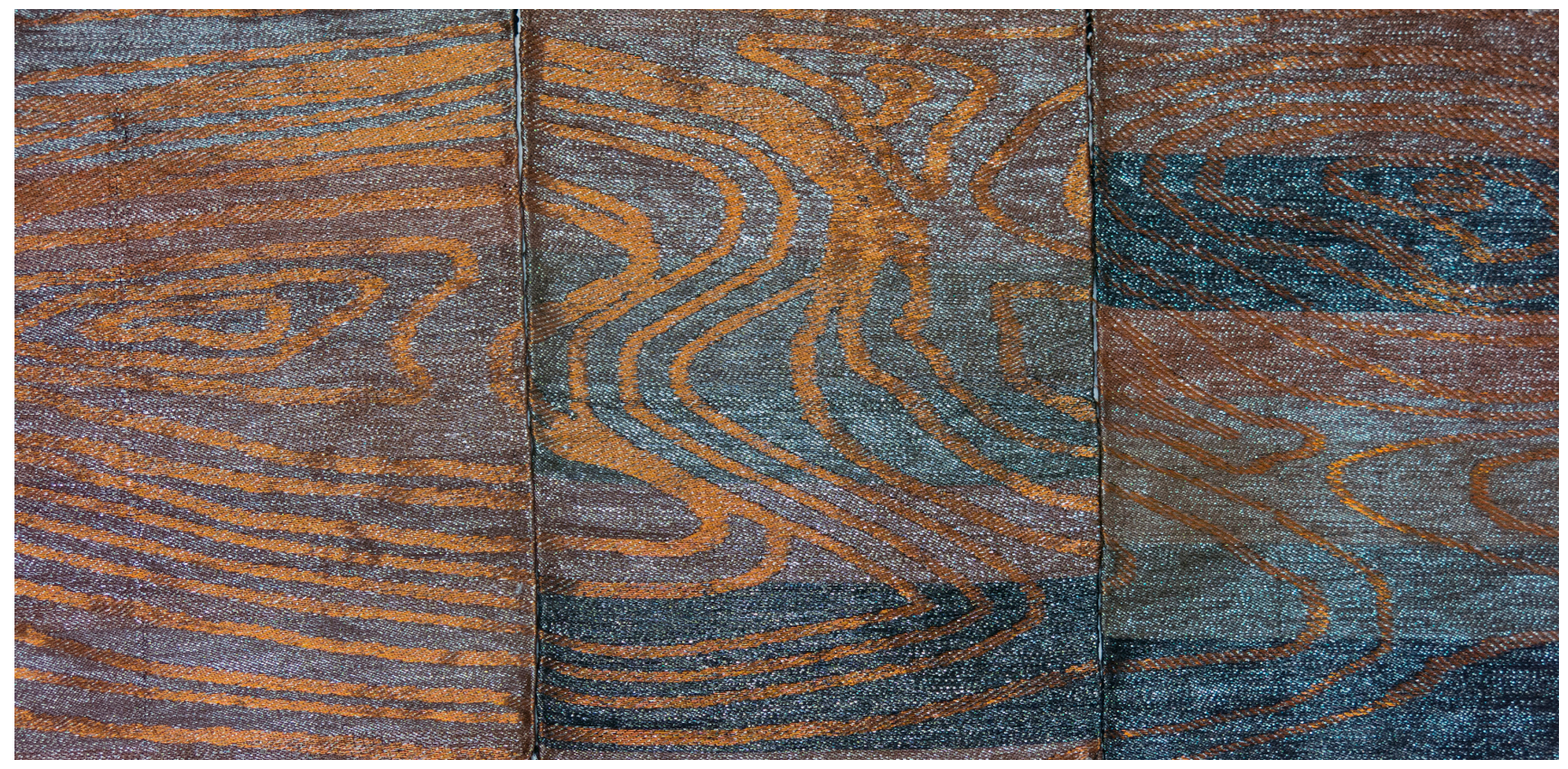

Figure 3. Ruth Beer. Seep. 2014. Three panel Jacquard woven tapestry; copper magnetic wire, plastic audio magnetic tape, $76 \times 182 \mathrm{~cm}$. Image courtesy of the artist.

Elements of conversation and dialogue permeate many aspects of the "Trading Routes" arts-based research. How to best utilize the concept of "voice" in form became a deep component of our a/r/tographic praxis. Seep (fig. 3), is made from copper wire and plastic audio magnetic tape. The petroleum-based plastic film is unwound from the spools inside discarded cassette tapes. Despite being unable to be played in a conventional way, the unfurled tape nevertheless contains the acoustic information imprinted within. The residue of culture and sounds are embedded in the magnetic fibres. The weaving reframes popular culture, in the form of "classic" or "hit" songs, within an emergent and material dialogue on resource industries. The tapestry weaving depicts coppery lines radiating out across a silvery black background. Seep suggests a shift away from the height and depth of elevation of a work like Oil Topography, and 
more towards a horizontal spread. The irregular expanding forms have multiple points of origin in the work. The two largest points begin in the first and the last panel. The center panel presents the viewer with a section that feels the force of two trajectories pressing up against one another. Two echoes, perhaps, or sonic rings.

Our investment in understanding the dialogical potential of extracted resources rebounds off of the work Harold Innis, once again. For Innis, "the 'staples' in Canadian economic history were communicative media in their own right" (Kroker 115). This is a remarkable suggestion, one that implies that resources articulate their own relationship to empires and nations, and that "staples" can speak to the complex preoccupations of a country. Seep joins in for the refrain of that conversation, by presenting a cacophony of other voices. The visual experience of the weaving is bound with a muted, but ever-present suggestion of sound, audio, dialogue. Though less apparent as a visual representation of oil, the filmy petro-plastic that is woven into Seep identifies a relationship to both land and oil through its communicative qualities.

An exploration of communications networks is a research strategy for rethinking ways in which publics can engage with petroleum industries. Loop (fig. 4 ) is a weaving of magnetic audiotape and dyed cotton. In this work's reference to duration, the cassette tape becomes a string that is measured not in distance but in time: hours, minutes, the chronology of recorded seconds. In the markets, oil continues to be measured in barrels, but it is socially understood in terms of time. Peak oil and the end of oil are dated in years, in months, measured from the base unit of the

Figure 4. Ruth Beer. Loop. 2014. Audio magnetic tape and indigo-dyed cotton, $243 \times$ $106 \times 30 \mathrm{~cm}$. Exhibited in Mineral Matters at Kimura Gallery. University of Alaska, Anchorage. Image courtesy of the artist. 
present. The depletion of reserves is not a function of how much (or little) is left, but of how quickly it is siphoned up. When installed against the wall, the long swatch is looped over itself, creating a pucker at the bottom. The loop brings one end of the weaving up towards the other, but the ends sit side by side on a flat rod and do not join up again. The emphasis is placed on the realization that this loop is not infinite. Like the audio loop that sounds disjointed, or skipped rather than continuous, there is an audio-visual break in this work.

Material experimentation is a major part of our project's research, and it has furthered a theoretical understanding of the relationship between fibers and land. Each material has come to the project through a different route, bears a different relationship to the contemporary landscape, and finds itself both entangled and emergent in the complex matrix of the weaving. The use of diverse and unconventional fibers opens up new points of connectivity between issues of land, land use, Indigenous rights, and resource extraction through the aesthetic experience. Such an analytical exploration of these woven fibers is indicative of the interest in the ability of oil (and other resources) to be seen within a broader field of communications.

\section{Networks}

Disparate research interests align to enrich one another in the "Trading Routes" scholarship. To pursue these research concerns through critical-aesthetic reflections is to also "invite wider participation in the production of resource knowledge [...] to employ the destabilizing and reframing qualities of aesthetics" (Biemann et al. 76). The destabilizing experience that can be offered by aesthetics is one that opens up new kinds of associations, allowing the viewer to stretch their understandings about the world. Weaving practices are intimately bound up with networking structures, and as a result, they provide a remarkable pivot point from which understandings of connectedness can be formed. In addition to the Jacquard weavings used for image production, woven nets have also been important aspects of production in relation to this project. Perhaps more pointedly than other fiber-based materials, nets, and networks, are utilitarian. Whether for trapping, catching, gathering, or connecting, they are purposeful branches of technical knowledge requiring active agents. Given that "nets have an organizing and structuring, an adhesive and an inclusive function," they also "facilitate sociality and power in equal measure," (Böhme 53). How could we be better in/formed of feedback systems linking the many interlaced stakeholders of resource extraction? Within our research we sought opportunities to create social bonds and co-learning, using craft as a way of fostering skill-sharing. 
To do this, our research turned us towards the first early instance of "networking" in Canada's colonial past. It is no coincidence that Innis' research concerns overlapped the fields of resource economics and communications theory. Technologies like the telegraph and the railway, aided by profits from the fur trade and the exchange of textiles, were required to unite the vast and disparate geographies of Canada in the nineteenth century. Centralized control of communication networks like radio and television was needed to sustain those linkages and create the appearance of a unified nationality. Broadcasting infrastructure never quite separated from the discourse on resources, as government and companies like the Hudson's Bay Company later mandated "to establish modern communications in its territories and to control the development of resources" (Otter 175; emphasis added). To achieve this, infrastructure needed to be built to facilitate the invention of networks on an unprecedented scale. In July of 1863 , an order was placed by Edward Watkins with funds from the Hudson's Bay Company for "nearly two hundred tons of copper wire to be delivered to several points in the Northwest" (Otter 175). Faster than the railway, copper trumped all the other conductors and laid the grounds for the information highways to come.

Antenna 1 (fig. 5) is a copper wire net whose varied woven structures are delicately gauged. The mesh of the net allows the ductile copper wire to be adjusted, so it waves in and out, towards and away from the viewer. Referencing its electronic communicative potential, the sculpture-as-antenna captures radio waves, which carry signals across the maritime space and into the gallery, emanating as

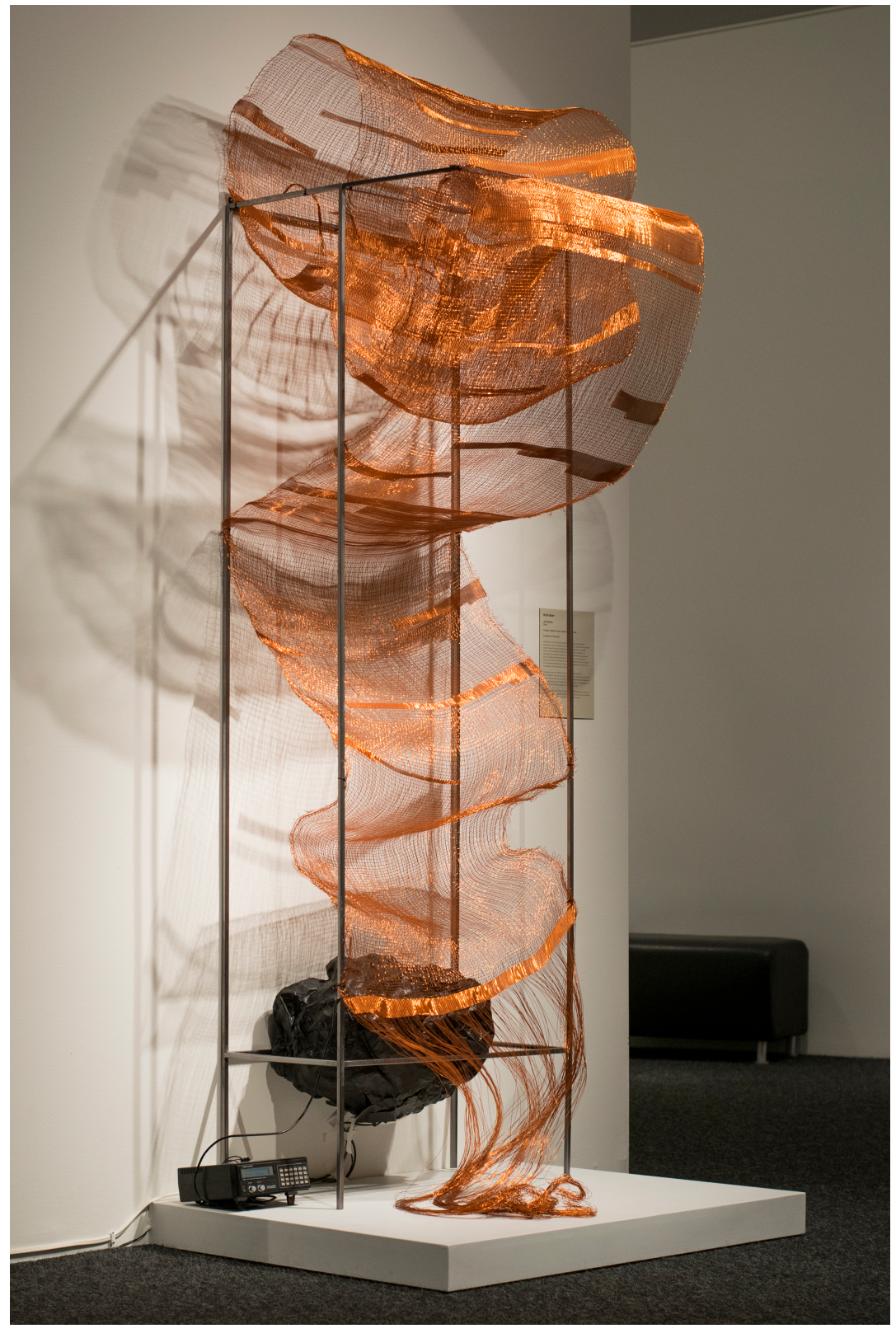

Figure 5. Ruth Beer. Antenna 1. 2016. Copper magnetic wire net, polyurethane, broadband radio. Installed at the Bellevue Museum. Bellevue, Washington. Image credit: Emilie Smith. 
unstable auditory broadcasts through the broadband radio. From traffic control to weather reports, Antenna 1 positions the relationship between resource extraction and waterways amidst a network of communicative potential.

While Antenna 1 makes use of the short-wave radio, the exhibition of this work serves as a reminder that the dialogical networks regarding extraction are not confined to national boundaries, but exist on a global scale, and amidst international markets. The expansion of crude oil pipelines in Canada will suggest a different kind of connective network not only between provinces, but globally as well. In 2016, Antenna 1 was exhibited Bellevue Washington in the Bellevue Arts Museum's Biennial. The exhibition, entitled "Metalmorphosis," presented work of Canadian and American artists, craftspeople, and designers living along the Northwest (from Alaska down to Oregon) whose work engaged with the destructive and constructive qualities of metal. Issues of mining, extraction, and the molten or solid properties of metal were some of the major themes explored. One visitor to the exhibition noted that they had never before considered the variations of "expansive, volumetric qualities of metal," and that their experience viewing Antenna 1, specifically, led them to newly understand metal's "ability to be both formless and any form at all, flowing through the space like soft waves" (Gallow). Here, the viewer creates a connection between metal and water, and also reconsiders the formal potential of the material. In an attempt to materially and aesthetically inform publics about the pervasiveness of extraction industries, and their resulting effects on aquatic ecosystems, this reflection is indicative of the way in which arts-based research makes these kinds of insights possible.

Our a/r/tographic approach also bears many affinities with net-based structures (Irwin et al.). The concept of the "net" allows multiple theoretical positions to be accessed at once; an essential feature of both contemporary energy discourse, and arts-based research. With nets, "the potency is embodied by means of pulling the nodal intersections of arbitrary connecting lines between innumerable points and thus linking them into a coarse-meshed overall structure" (Schneider 331). Fossil fuels permeate nearly every area of contemporary life, and the theoretical understanding of the phenomena must be similarly polyvalent. The proposed pipelines will funnel chemically diluted bitumen, but they will also shape and redirect the ways in which land is used, settled or abandoned (both directly along the proposed routes, and elsewhere affected by the movement of laborers); what prospects of employment are available; how autonomy is supported in unceded Indigenous territory; and what kinds of agency the Canadian public has to untangle the implications of such a project. 


\section{Conclusion}

Much of the endeavor of "Trading Routes" is to see oil within the framework of a critical humanism; to see oil as necessarily bound up with cultural expectations, organizations, and traditions. This approach is meant to refuse to treat oil as simply a commodity, and to work with the imperative "need for new discourses and modes of representation that will shift resource-related issues from a market-driven domain to one of engaged public debate" (Biemann et al. 77). As the negotiations of the proposed pipelines in British Columbia remain to be resolved, the artworks' speculative treatment is informed by the past, by other industries, by local knowledge, and by diverse cultural perspectives. To the rallies, marches, and civil disobedience spurred by these proposals, the project clears space for a contemplative form of activism. In this paper, we have examined how weaving is a significant component of this exploration, a medium that traces its own route through the colonial past of Canada to the present.

Aligning oil with the woven goods of the past, is to also align oil with the power to found, to colonize, to constitute a nation. As the power of the oil industry becomes more and more visible, the use of unconventional carbon reserves becomes more contested. Where environmental debates tend to polarize public opinion to the point of impasse, "Trading Routes" manipulates the contradictions within, seeking more informal, or a/r/tographic approaches in/form. Art and research are seen in a hybridized and integrated view, creating artworks as a process of inquiry, and textiles that communicate research in the world. Weaving makes possible a tactile and experiential contribution to political metaphor. Through new and provocative aesthetics, the project has offered a number of opportunities to change our behaviors, social politics, and relationship to the land. This work endeavors to support active democratic participation, and results in opportunities for voice that take place outside the conventional channels of activism. Our strategy operates much like the selvage of a woven fabric, the selffinished edge that is created by looping the divergent trajectories of the warp and the weft together. Perhaps, this is the kind of edge to energy discussions that is needed to mend the tears, to salvage productive discourse and to create stimulus for broader action. 


\section{WORKS CITED}

"2015 Annual Report". Gulf of Georgia Cannery Society, http://gulfofgeorgiacannery.org/wp-content/uploads/ 2015AnnualReport website.pdf. Accessed 24 April 2018.

Adamson, Glenn. The Invention of Craft. Bloomsbury Academic, 2013.

After Oil. Edited by Imre Szeman and the Petrocultures Research Group. Petrocultures Research Group, 2016.

Auther, Elissa. String, Felt, Thread: The Hierarchy of Art and Craft in American Art. University of Minnesota Press, 2010.

Bresler, Liora. "Toward Connectedness: Aesthetically Based Research." Studies in Art Education, vol. 48, no. 1, 2006, pp. 52-69. JSTOR, www.jstor.org/stable/25475805.

Biemann, Ursula., Peter Mörtenböck, and Helge Mooshammer. "From Supply Lines to Resource Ecologies." Third Text, vol. 27, no. 1, Jan. 2013, pp. 76-94. EBSCOhost, doi:10.1080/09528822.2013.752199.

Böhme, Hartmut. "Mythology and Aesthetics of the Textile." Art and Textiles: Fabric as Material and Concept in Modern Art from Klimt to the Present, edited by M. Bruderlin, Hatje Cantz Verlag, 2013, pp. 46-69.

"Eulachon (Pacific Population)." Fisheries and Oceans Canada, 26 Feb. 2018, http:// www.dfo-mpo.gc.ca/species-especes/profiles-profils/eulachon-eulakane-paceng.html. Accessed 29 Jan. 2019.

Gallow, Lauren. "BAM Biennial 2016: Metalmorphosis". Art Access, 2 Nov. 2016, http://www. artaccess.com/articles/4361729. Accessed 24 Apr. 2018.

Hern, Matt and Am Johal. Global Warming and the Sweetness of Life: A Tar Sands Tale. MIT Press, 2018.

Innis, Harold A. The Bias of Communication. Toronto University Press, 1951. 
---. The Fur Trade in Canada: An Introduction to Canadian Economic History. Toronto University Press, 1970.

Irwin, Rita. L., Ruth Beer, Stephanie Springgay, Kit Grauer, Gu Xiong, and Barbara Bickel. "The Rhizomatic Relations of A/R/Tography." Studies in Art Education, vol. 48, no. 1, 2006, pp. 70-88. JSTOR, www.jstor.org/stable/ 25475806.

Kroker, Arthur. Technology and the Canadian Mind: Innis / McLuhan / Grant. New World Perspectives, 1984.

Leavy, Patricia. Method Meets Art: Arts-Based Research Practice. Guilford Press, 2008.

LeMenager, Stephanie and Stephanie Foote. "The Sustaining Humanities". PMLA, Vol. 127, No. 3 (May 2012), pp. 572-578. JSTOR, www.jstor.org/stable/41616848

McCullough, Malcolm. Abstracting Craft: The Practiced Digital Hand. MIT Press, 1996.

Moody, Megan Felicity. Eulachon Past and Present. MSci., University of British Columbia, 2008, http://www.dfo-mpo.gc.ca/Library/333713.pdf. Accessed 24 April 2018.

Otter, A.A. "Transportation and Transformation: The Hudson's Bay Company, 1857-1885." Great Plains Quarterly, vol. 3, no. 3, 1983, pp. 171-185. JSTOR, www.jstor.org/stable/23530924.

Plant, Sadie. Zeros and Ones: Digital Women and the New Technoculture. Fourth Estate, 1991.

Robertson, Kirsty and Lisa Vinebaum. "Editorial: Crafting Community." TEXTILE, vol. 14, no. 1, 2016. Taylor \& Francis Online, doi:

10.1080/14759756.2016.1084794.

Robinson, Eden. Monkey Beach. Vintage Canada, 2000.

Rogoff, Irit. "Practicing research: Singularising knowledge". MaHKUzine, Summer 2010, pp. 37- 42, http://www.mahku.nl/download/maHKUzine09 web.pdf. Accessed 24 April 2018. 
Rose, Gillian. Visual Methodologies. SAGE Publications Ltd., 2001.

Schneider, Birgit. "Caught in the Tangle of the Net: On a History of the Network Metaphor." Art and Textiles: Fabric as Material and Concept in Modern Art from Klimt to the Present, edited by M. Bruderlin. Hatje Cantz Verlag, 2013, pp. 330-337.

Soper-Jones, Ella. "The Fate of the Oolichan: Prospects of Eco-Cultural Restoration in Eden Robinson's Monkey Beach." Journal of Commonwealth Literature, vol. 44, no. 2, 2009, pp. 15-33. SAGE Publications, dot: 10.1177/0021989409105116.

"Steveston Recollections." Virtual Museum Community Stories, 2019, http:// www.virtualmuseum.ca/sgc-cms/histoires_de_chez_nous-community_stories/ pm_v2.php?id=exhibit_home\&fl=0\&lg=English\&ex $=00000591$.

Sullivan, Graeme. Art Practice as Research: Inquiry in Visual Arts. $2^{\text {nd }}$ ed., SAGE Publications Ltd., 2010.

White, John Howell, Charles Garoian, and Elizabeth Garber. "Speaking in Tongues: The Uncommon Ground of Arts-Based Research." Studies in Art Education, vol. 51, no. 2, 2010, pp. 134-146. JSTOR, JSTOR, www.jstor.org/stable/40650458.

Willmott, Cory. "From Stroud to Strouds: The Hidden History of a British Fur Trade Textile." Textile History, vol. 36, no. 2, Nov. 2005, pp. 196-234. EBSCOhost, doi:10.1179/004049605x61564. 